\title{
Prevalence and Risk Factors of Antenatal Depression among Omani Women in a Primary Care Setting Cross-sectional study
}

"Mohammed Al-Azri, ${ }^{1}$ Iman Al-Lawati, ${ }^{2}$ Raya Al-Kamyani, ${ }^{2}$ Maisa Al-Kiyumi, ${ }^{2}$ Aisha Al-Rawahi, ${ }^{2}$ Robin Davidson, ${ }^{3}$ Abdullah Al-Maniri ${ }^{4}$

$$
\begin{gathered}
\text { الاكتئاب في فترة الحمل معدل انتشاره وأسبابه في النساء العمانيات في بجال } \\
\text { الرعاية الصحية الأولية دراسة مستعرضة }
\end{gathered}
$$

محمد العزري، ايمان اللواتية، ريا الكميانية، مايسة الكيومية، عائشة الرواحية، روين ديفدسون، عبداله المنيري

ABSTRACT: Objectives: This study aimed to identify the prevalence of antenatal depression and the risk factors associated with its development among Omani women. No previous studies on antenatal depression have been conducted in Oman. Methods: This descriptive cross-sectional study was carried out between January and November 2014 in Muscat, Oman. Pregnant Omani women $\geq 32$ gestational weeks who were attending one of 12 local primary care health centres in Muscat for routine antenatal care were invited to participate in the study $(\mathrm{n}=986)$. An Arabic version of the validated self-administered Edinburgh Postnatal Depression Scale questionnaire was used to measure antenatal depression. A cut-off score of $\geq 13$ was considered to indicate probable depression. Results: A total of 959 women participated in the study (response rate: 97.3\%). Of these, 233 were found to have antenatal depression (24.3\%). A bivariate analysis showed that antenatal depression was associated with unplanned pregnancies $(P=0.010)$, marital conflict $(P=0.001)$ and a family history of depression $(P=0.019)$. The adjusted odds ratio (OR) after logistic multivariate regression analysis showed that antenatal depression was significantly associated with unplanned pregnancies (OR: 1.37; 95\% confidence interval [CI]: 1.02-1.86) and marital conflict (OR: 13.83; 95\% CI: 2.99-63.93). Conclusion: The prevalence of antenatal depression among the studied Omani women was high, particularly in comparison to findings from other Arab countries. Thus, antenatal screening for depression should be considered in routine primary antenatal care. Couples should also be encouraged to seek psychological support should marital conflicts develop during pregnancy.

Keywords: Pregnancy; Depression; Prevalence; Risk Factors; Women; Primary Health Care; Oman.

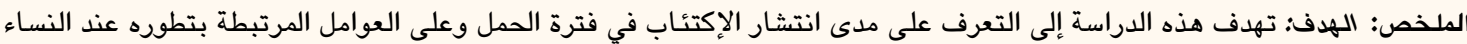

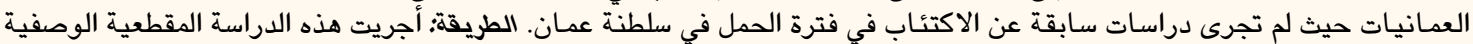

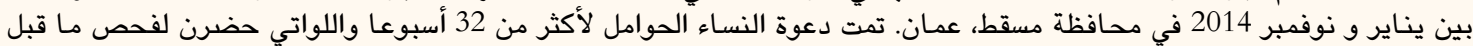

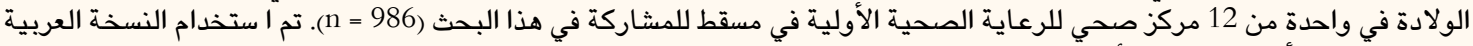

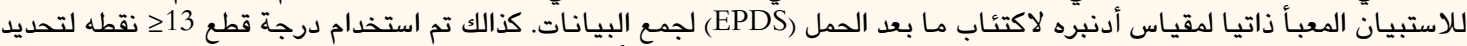

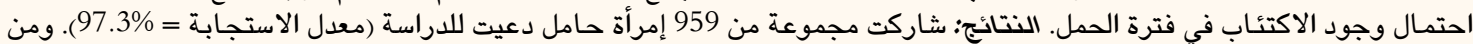

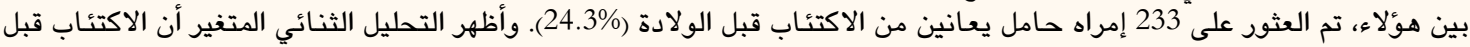

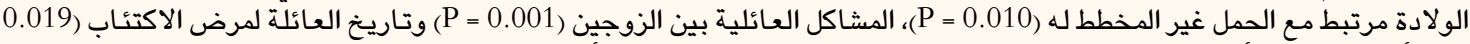

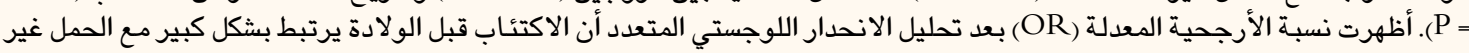

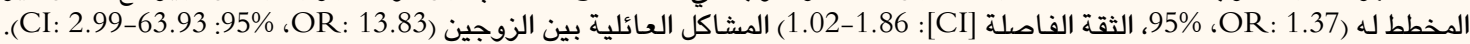

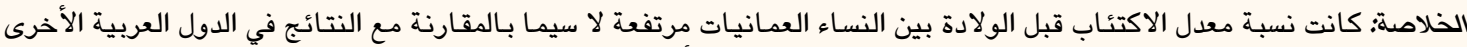

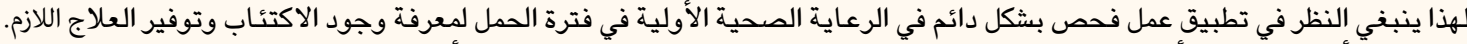

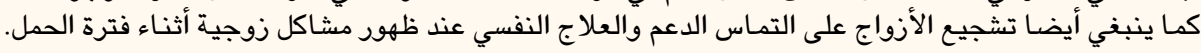
مفتاح الكلمات: الحمل؛ الاكتئاب؛ المعدل؛ عوامل الخطر؛ النساء؛ الرعاية الصحية الأولية؛ عمان. 


\section{Advances in KNOWLedge}

This study is the first in Oman to investigate the prevalence and risk factors of antenatal depression.

The rate of antenatal depression among the studied Omani women was high in comparison to rates observed in other countries in the Middle Eastern region.

Among the cohort of Omani pregnant women, antenatal depression was significantly associated with unplanned pregnancies, marital conflict and a family history of depression.

\section{Application to Patient Care}

Due to the high rate of antenatal depression found in this study, depression screening should be considered as part of routine antenatal care. This will allow women with antenatal depression to be identified earlier and provided with adequate treatment and support.

Considering that marital conflict was a significant risk factor for antenatal depression, Omani couples should be encouraged to seek psychological support if this type of conflict arises during pregnancy.

$\mathrm{D}$ EPRESSION IS A COMMON ALTHOUGH often misdiagnosed disorder that can affect women during the antenatal period. While the prevalence of antenatal depression varies between countries, it is generally more common than postnatal depression., ${ }^{2,3}$ Antenatal depression is often associated with considerable medical and psychological morbidities which affect both the mother and baby. Research has shown that antenatal depression increases the risk of pre-eclampsia, operative deliveries (e.g. Caesarean sections or instrumental vaginal deliveries), use of epidural analgaesics during delivery, spontaneous preterm births, postnatal depression and suicidal ideation. ${ }^{4-6}$ For the baby, antenatal depression is known to increase the risk of slower fetal activity, low birth weight, subsequent admission to the neonatal care unit and sudden death. ${ }^{6}$ In addition, the infants of women with antenatal depression may receive suboptimal physical and psychological care after birth and older children and/or spouses can also suffer from the secondary effects of maternal depression. ${ }^{7,8}$ Consequently, increased awareness and early identification of antenatal depression with appropriate psychotherapeutic interventions could reduce the risk of adverse effects for the mother, child and family. ${ }^{1,7,8}$

Several sociodemographic, psychiatric and medical factors have been associated with an increased risk of developing antenatal depression. Low socioeconomic and educational status, low levels of social support, unplanned pregnancies and spousal violence have been associated with the condition. ${ }^{9-11}$ Psychological and psychiatric factors include the existence of psychosocial problems such as depression, stress, anxiety, low self-esteem, poor partner relationships, forced sexual relations and a history of traumatic abuse; these factors may either affect the woman herself or other family members. ${ }^{3,11,12}$ Finally, excessive consumption of alcohol and iron deficiency anaemia have been linked to the development of antenatal depression. ${ }^{11}$

Oman is a developing country located on the southeastern tip of the Arabian Peninsula. In 2010, the national census recorded a total population of 2.7 million, of which 1.9 million were Omani. ${ }^{13}$ Approximately $35 \%$ of Omanis were aged below 15 years and only $3.5 \%$ were aged above 65 years (median age: 22 years). ${ }^{13}$ In 2010, approximately $21 \%$ of the total population resided in the capital city, Muscat, which is the most populated city in Oman. ${ }^{13}$ Primary healthcare is considered the first port of entry to all levels of healthcare in Oman. By means of the Ministry of Health $(\mathrm{MOH})$, the Omani government funds and provides free healthcare services to all Omanis, as well as non-Omanis working in the government sector. In Muscat, standard antenatal services are available in the antenatal clinics of 27 local primary care health centres, each of which provides care to the population in their specific catchment area. ${ }^{14}$ In general, a total of six visits are required during a normal low-risk pregnancy while higher-risk pregnancies are referred to antenatal clinics in secondary or tertiary hospitals depending on the severity of the condition. ${ }^{15}$ However, no screening measures currently exist within $\mathrm{MOH}$ antenatal care protocols to identify women with antenatal depression. ${ }^{15}$ To the best of the authors' knowledge, no studies have yet been conducted in Oman to identify the prevalence of antenatal depression and its potential sociodemographic correlates. The aim of this study, therefore, was to assess the prevalence of antenatal depression among Omani women and explore associated clinical and demographic risk factors.

\section{Methods}

This descriptive cross-sectional study was carried out between January and November 2014 in Muscat, Oman. The required sample size for the current study was estimated to be approximately 1,600, based on an assumed 20\% prevalence of antenatal depression a 95\% confidence interval (CI) and a 10\% error in estimating the prevalence of depression. Of the 27 local primary care health centres in Muscat, 12 centres were randomly selected for inclusion in the study. A 
Table 1: Sociodemographic and clinical characteristics of pregnant Omani women receiving antenatal care in local primary care health centres $(\mathrm{N}=959)$.

\begin{tabular}{|c|c|}
\hline Characteristic ${ }^{*}$ & n (\%) \\
\hline Age in years & $957(100.0)$ \\
\hline$<24$ & $261(27.3)$ \\
\hline $25-30$ & $451(47.1)$ \\
\hline$>30$ & $245(25.6)$ \\
\hline Occupation & $959(100.0)$ \\
\hline Housewife & $609(63.5)$ \\
\hline Employed & $350(36.5)$ \\
\hline Education level & $957(100.0)$ \\
\hline Primary and secondary & $519(54.2)$ \\
\hline University & $438(45.8)$ \\
\hline Monthly income in Omani riyals & $957(100.0)$ \\
\hline$<500$ & $298(31.1)$ \\
\hline $500-1,000$ & $488(51.0)$ \\
\hline$>1,000$ & $171(17.9)$ \\
\hline Gravidity & $959(100.0)$ \\
\hline Primigravida & $373(38.9)$ \\
\hline Multigravida & $465(48.5)$ \\
\hline Grand multigravida & $121(12.6)$ \\
\hline Gestational age in weeks & $959(100.0)$ \\
\hline $32-34$ & $399(41.6)$ \\
\hline $35-37$ & $376(39.2)$ \\
\hline$>37$ & $184(19.2)$ \\
\hline Anaemia status ${ }^{+}$ & $958(100.0)$ \\
\hline Normal & $255(26.6)$ \\
\hline Mild anaemia & $488(50.9)$ \\
\hline Moderate-to-severe anaemia & $215(22.4)$ \\
\hline History of miscarriage & $959(100.0)$ \\
\hline Yes & $170(17.7)$ \\
\hline No & $789(82.3)$ \\
\hline History of depression & $959(100.0)$ \\
\hline Yes & $10(1.0)$ \\
\hline No & $949(99.0)$ \\
\hline Family history of depression & $959(100.0)$ \\
\hline Yes & $19(2.0)$ \\
\hline No & $940(98.0)$ \\
\hline Planned pregnancy & $958(100.0)$ \\
\hline Yes & $560(58.5)$ \\
\hline No & $398(41.5)$ \\
\hline
\end{tabular}

$\begin{array}{lc}\text { Marital conflict } & \mathbf{9 5 8 ( 1 0 0 . 0 )} \\ \text { Yes } & 13(1.4) \\ \text { No } & 945(98.6)\end{array}$

*The total of each characteristic corresponds to the number of respondents for each question. ${ }^{\dagger}$ Haemoglobin levels of $<11.0 \mathrm{gm} / \mathrm{dL}$.

total of 986 pregnant Omani women $\geq 32$ gestational weeks attending one of these 12 centres for routine antenatal care during the study period were invited to participate in the study. Women who were nonOmani, currently receiving treatment for depression, or diagnosed with gestational diabetes, hypertension or pregnancy-induced hypertension were excluded.

The Arabic version of the self-administered Edinburgh Postnatal Depression Scale (EPDS) questionnaire was used to measure antenatal depression. ${ }^{3,16}$ Mohammad et al. first translated into Arabic, validated and successfully used the EPDS questionnaire in a study conducted in Jordan, an Arab country with similar cultural and sociodemographic characteristics to Oman. ${ }^{3}$ The EPDS is a widely validated questionnaire used to identify and measure depression in the antenatal and postnatal periods. ${ }^{3,5,17}$ The first part of the questionnaire included 12 items designed to determine the sociodemographic and medical characteristics of the participants, including age, occupation, education level, monthly income, gravidity, gestational age, anaemia status (haemoglobin levels $<11.0 \mathrm{gm} / \mathrm{dL}$ ), history of miscarriage, history of depression, family history of depression, whether the pregnancy was planned or spontaneous and marital conflict. The second part constituted 10 questions to determine the presence of antenatal depression. Each question was scored from $0-3$ with a total score ranging from $0-30$. A cut-off score of $\geq 13$ was considered to indicate probable antenatal depression. ${ }^{3,5}$ Three nurses in each of the primary care health centres included in the study were trained to distribute and collect the questionnaires from the study subjects, although the questionnaires were completed solely by the participants. The reliability of the items was tested on a sample of 30 women, which indicated a Cronbach's alpha value of 0.75 . These women were subsequently included in the study.

Data were analysed using the Statistical Package for the Social Sciences (SPSS), Version 20 (IBM Corp., Chicago, Illinois, USA). All variables were subjected to univariate analysis using Pearson's Chi-squared test to determine associations between antenatal depression and sociodemographic characteristics. A $P$ value of $\leq 0.050$ was considered statistically significant. To adjust for possible confounding factors, a second analysis 
Table 2: Associations between antenatal depression* and sociodemographic variables among pregnant Omani women receiving antenatal care in local primary care health centres $(\mathrm{N}=959)$.

\begin{tabular}{|c|c|c|c|}
\hline \multirow[t]{2}{*}{ Variable $^{+}$} & \multicolumn{2}{|c|}{ n (\%) } & \multirow[t]{2}{*}{$P$ value } \\
\hline & $\begin{array}{c}\text { Depressed } \\
(\mathrm{n}=233)\end{array}$ & $\begin{array}{c}\text { Not } \\
\text { depressed } \\
(\mathbf{n}=726)\end{array}$ & \\
\hline \multicolumn{3}{|c|}{ Age in years $(n=957)$} & 0.917 \\
\hline$<24$ & $66(25.3)$ & $195(74.7)$ & \\
\hline $25-30$ & $108(23.9)$ & $343(76.1)$ & \\
\hline$>30$ & $59(24.1)$ & $186(75.9)$ & \\
\hline \multicolumn{3}{|c|}{ Occupation $(n=959)$} & 0.399 \\
\hline Housewife & $154(25.3)$ & $455(74.7)$ & \\
\hline Employed & $80(22.9)$ & $270(77.1)$ & \\
\hline \multicolumn{3}{|c|}{ Education level $(\mathbf{n}=957)$} & 0.127 \\
\hline $\begin{array}{l}\text { Primary and } \\
\text { secondary }\end{array}$ & $137(26.4)$ & $382(73.6)$ & \\
\hline University & $97(22.1)$ & $341(77.9)$ & \\
\hline \multicolumn{3}{|c|}{ Monthly income in Omani riyals $(\mathrm{n}=957)$} & 0.078 \\
\hline$<500$ & $86(28.9)$ & $212(71.1)$ & \\
\hline $500-1,000$ & $106(21.7)$ & $382(78.3)$ & \\
\hline$>1,000$ & $42(24.6)$ & $129(75.4)$ & \\
\hline \multicolumn{3}{|c|}{ Gravidity $(\mathbf{n}=959)$} & 0.923 \\
\hline Primigravida & $89(23.9)$ & $284(76.1)$ & \\
\hline Multigravida & $114(24.5)$ & $351(75.5)$ & \\
\hline $\begin{array}{l}\text { Grand } \\
\text { multigravida }\end{array}$ & $31(25.6)$ & $90(74.4)$ & \\
\hline \multicolumn{3}{|c|}{ Gestational age in weeks $(n=959)$} & 0.338 \\
\hline $32-34$ & $107(26.8)$ & $292(73.2)$ & \\
\hline $35-37$ & $85(22.6)$ & $291(77.4)$ & \\
\hline$>38$ & $42(22.8)$ & $142(77.2)$ & \\
\hline \multicolumn{3}{|c|}{ Anaemia status $^{\ddagger}(\mathrm{n}=958)$} & 0.941 \\
\hline Normal & $64(25.1)$ & $191(74.9)$ & \\
\hline Mild anaemia & $117(24.0)$ & $371(76.0)$ & \\
\hline $\begin{array}{l}\text { Moderate-to- } \\
\text { severe anaemia }\end{array}$ & $53(24.7)$ & $162(75.3)$ & \\
\hline \multicolumn{3}{|c|}{ History of miscarriage $(\mathbf{n}=959)$} & 0.765 \\
\hline Yes & $43(25.3)$ & $127(74.7)$ & \\
\hline No & $191(24.2)$ & $598(75.8)$ & \\
\hline \multicolumn{3}{|c|}{ History of depression $(n=959)$} & 0.058 \\
\hline Yes & $5(50.0)$ & $5(50.0)$ & \\
\hline No & 229 (24.1) & 720 (75.9) & \\
\hline
\end{tabular}

Family history of depression $(\mathbf{n}=959)$

$0.019^{\Im}$

$\begin{array}{ccc}\text { Yes } & 9(47.4) & 10(52.6) \\ \text { No } & 225(23.9) & 715(76.1)\end{array}$

Planned pregnancy $(\mathbf{n}=958)$

$0.010^{\Im}$

Yes $\quad 120(21.4) \quad 440(78.6)$

No $\quad 114(28.6) \quad 284(71.4)$

Marital conflict $(n=958)$

$0.001^{\S}$

$\begin{array}{ccc}\text { Yes } & 11(84.6) & 2(15.4) \\ \text { No } & 223(23.6) & 722(76.4)\end{array}$

*Antenatal depression was self-assessed by respondents using the Arabic version of the 22-item Edinburgh Postnatal Depression Scale questionnaire. ${ }^{3,16}$ A score of $\geq 13$ was considered to indicate probable antenatal depression. ${ }^{3,5}$ The total of each variable corresponds to the number of respondents for each question ${ }^{*}$ Haemoglobin levels of $<11.0$

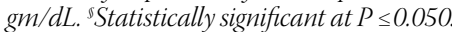

was conducted using multivariate logistic regression for variables that showed significant associations with antenatal depression at the $P \leq 0.050$ level.

This study was approved by the Medical Research \& Ethics Committee of the College of Medicine \& Health Sciences at Sultan Qaboos University (MREC \#572). Written consent was obtained from each of the subjects before their participation in the study.

\section{Results}

A total of 959 pregnant Omani women participated in the study (response rate: $97.3 \%$ ). The mean age of the participants was $27 \pm 4.8$ years (range: $17-43$ years old). The majority of participants were housewives (63.5\%). More than half of the participants (54.2\%) had only completed primary and secondary education while $45.8 \%$ had a university qualification. In terms of gravidity, $48.5 \%$ were multigravidae, $12.6 \%$ were grand multigravidae and $38.9 \%$ were primigravidae. A total of

Table 3: Logistic regression analysis of risk factors for antenatal depression* among pregnant Omani women receiving antenatal care in local primary care health centres $(\mathrm{N}=959)$

\begin{tabular}{|c|c|c|c|}
\hline Variable & $\begin{array}{l}\text { Adjusted } \\
\text { OR }\end{array}$ & $95 \%$ CI & $P$ value \\
\hline $\begin{array}{l}\text { Family history of } \\
\text { depression }\end{array}$ & 2.04 & $0.76-5.47$ & 0.159 \\
\hline $\begin{array}{l}\text { Unplanned } \\
\text { pregnancy }\end{array}$ & 1.37 & $1.02-1.86$ & $0.040^{\dagger}$ \\
\hline Marital conflict & 13.83 & $2.99-63.93$ & $0.000^{\dagger}$ \\
\hline \multicolumn{4}{|c|}{$R=$ odds ratio; $C I=$ confidence interval. } \\
\hline
\end{tabular}


$41.6 \%$ of the women were between $32-34$ gestational weeks while $58.4 \%$ were $\geq 35$ gestational weeks. A history of miscarriage was reported by $17.7 \%$ of the participants. More than half the women (58.5\%) stated that their pregnancies were planned. A previous history or family history of depression was reported by $1.0 \%$ and $2.0 \%$ of the participants, respectively. The majority of the participants (98.6\%) reported no marital conflict. Mean haemoglobin levels were $10.9 \mathrm{gm} / \mathrm{dL}$. The majority of the participants were anaemic (73.3\%) [Table 1].

The EPDS scores ranged from 0-23 (mean: $9 \pm 4.8$ ). A total of 233 women had antenatal depression (24.3\%). A bivariate analysis showed that antenatal depression was significantly associated with unplanned pregnancies $(P=0.010)$, marital conflict $(P=0.001)$ and a family history of depression $(P=0.019)$ [Table 2]. Logistic multivariate regression analysis revealed that antenatal depression was significantly associated with unplanned pregnancies (OR: 1.37; 95\% CI: 1.02-1.86) and marital conflict (OR: 13.83; 95\% CI: 2.99-63.93) [Table 3]. The model fit $77.0 \%$ of cases correctly.

\section{Discussion}

The prevalence of antenatal depression in the studied group of Omani pregnant women was similar to that of a cohort in Brazil (24.3\%), but higher than findings from other countries with similar cultural and sociodemographic characteristics, such as Jordan (19.0\%) and Morocco (19.2\%).,18 Additionally, the prevalence was higher than results reported from Bangladesh, Turkey, Australia and the UK, but lower than the rate observed in South Africa (39.0\%). ${ }^{14,19-22}$ The high antenatal depression rate in South Africa has been attributed to a lack of partner support, high rates of intimate partner violence, low household incomes and the younger age of women during their pregnancies. ${ }^{23}$ Screening for antenatal depression has been recommended for developed countries by the American College of Obstetricians and Gynecologists. ${ }^{24}$ Considering the relatively high rate of antenatal depression observed in the current study, the $\mathrm{MOH}$ in Oman should consider implementing routine screening for the presence of antenatal depression as part of regular antenatal care services. Identifying women with antenatal depression would enable healthcare professionals to provide psychological support to those affected and hence potentially reduce the rate of antenatal depression and its related complications in Oman. ${ }^{3,17}$

Rich-Edwards et al. found that young maternal age was the strongest predictor of antenatal depression, as it was associated with financial hardship, unwanted pregnancies and a lack of partner support. ${ }^{25}$ In Oman, most women marry at a younger age, some as young as 16 years old, which may explain the higher prevalence of antenatal depression noted in the current study. ${ }^{26}$ Also, Oman, like many other developing countries, has a high fertility rate. ${ }^{27}$ Previous research shows that the more children in a family, the greater the prevalence of depression, as a result of increased psychosocial and financial demands. ${ }^{28}$ Nevertheless, neither maternal age nor gravidity were identified as factors significantly associated with antenatal depression in the current study.

Unplanned pregnancy was a significant risk factor for antenatal depression in the present cohort of Omani women. A planned pregnancy ensures that the woman is more prepared for the realities of pregnancy and childbearing whereas unplanned or unintended pregnancies may increase the risk of antenatal depression because of difficulties in balancing maternal needs and other responsibilities at home or work..$^{29}$ Women experiencing unplanned pregnancies are more likely to have an unstable psychosocial environment or feel a lack of security and attachment with their spouse. ${ }^{30}$ A previous study also indicated that couples with unplanned pregnancies experienced higher levels of marital conflict following delivery than couples with planned pregnancies. ${ }^{31}$ Women experiencing unplanned pregnancies are often unaware of their condition; as a result they do not initiate early prenatal care and may be more likely to engage in risky behaviours, such as drinking, smoking or illicit drug use. Kuroki et al. found that women with unplanned pregnancies had a lower vitamin intake during early pregnancy, which increased the risk of premature birth, low birth weight babies, infant abuse and neonatal death. ${ }^{32}$ Furthermore, one unplanned pregnancy was identified as a risk factor for subsequent unplanned pregnancies, particularly among young women with low education levels. ${ }^{33}$ Increased education about appropriate methods of contraception and approaches towards pregnancy planning are recommended in Oman.

The other significant risk factor for antenatal depression observed in the current study was marital conflict. The physiological and psychological changes that occur during pregnancy often influence women to seek out intimate partner support; consequently, the lack of such support may increase the likelihood of antenatal depression. ${ }^{34}$ Indeed, difficult or strained marital relationships marked by violence and disharmony have been shown to increase rates of antenatal depression. ${ }^{35,36}$ Likewise, greater marital distress has been reported by couples where the wife is depressed; these couples also resort to less constructive tactics to resolve their conflicts. ${ }^{35}$ Further exploration is needed 
regarding the nature of such conflicts and their role in the development of antenatal depression. In addition, future research is recommended to identify anxiety and depression among Omani women in the antenatal or postnatal periods, perhaps through the use of structured clinical interviews to validate the reliability of the EPDS questionnaire as a screening tool.

Although a previous history of depression was initially found to represent a risk factor for antenatal depression in the current study, this association was not significant after multivariate analysis. This may perhaps be due to the low reported rates of past or family history of depression; as is the case in several other Arab countries, many women in Oman believe that psychiatric illness is a social stigma. ${ }^{37}$ They may feel ashamed to be known to have a psychiatric illness and may hide their condition and refuse to seek medical help. Some women prefer to rely on their faith or turn to religious leaders for help. ${ }^{38}$ Al-Adawi et al. noted that Omanis tend to express their psychological problems in terms of physical symptoms in order to avoid the stigma attached to a psychiatric diagnosis. ${ }^{37}$

The current study is subject to certain limitations. First, as data were gathered from responses to a self-reported questionnaire, the true prevalence of antenatal depression may have been over- or underestimated. Additionally, the choice of cutoff value for EPDS scores was based on Jordanian research; although Oman has a similar culture, there may have been other differences between cohorts which could have affected the results. ${ }^{3}$ Indeed, it is not clear if the EPDS questionnaire has yet been established to have cross-cultural construct and criterion validity. Second, this study was descriptive and did not use objective criteria to diagnose antenatal depression; while the EPDS screens for antenatal depression, it is not intended as a diagnostic tool. ${ }^{16}$ Third, the crosssectional design of this study may have resulted in the inclusion of patients with pre-existing undiagnosed depression unrelated to pregnancy, although those with a known history of depression were excluded as far as possible. Conclusions about causative factors for depressive symptoms cannot be formulated based on the findings of this cross-sectional study; carefully designed prospective studies are recommended to identify possible causal relationships. Fourth, although the sample was large, the study was not designed to be truly epidemiological and the results reflect only women who presented to primary care centres. Fifth, women with previous diagnoses of depression, diabetes and hypertension were excluded; however, the presence of a pre-existing condition does not diminish the possibility that such women may develop antenatal depression. Finally, the required sample size calculated to estimate the prevalence of antenatal depression was not achieved due to a number of constraints.

\section{Conclusion}

This study was the first to assess the prevalence of antenatal depression and associated risk factors among a group of pregnant women in Oman. Findings indicated that antenatal depression was higher in Oman compared to other countries in the Middle Eastern region. Screening for the presence of antenatal depression should be included as a routine part of antenatal care. This will ensure that sufficient support can be provided to those affected. Antenatal depression was also significantly associated with unplanned pregnancies and marital conflict. As such, Omani women should be educated regarding appropriate methods of contraception and psychological support is recommended for couples experiencing marital conflict. Further large-scale research is required to determine the true rate of antenatal depression among Omani women.

\section{ACKNOWLEDGEMENTS}

The authors are grateful to Dr. Khitam. I. Mohammad, Professor Jenny Gamble and Professor Debra K. Creedy for permission to use the Arabic version of the EPDS in this research.

\section{CONFLICT OF INTEREST}

The authors declare no conflicts of interest.

\section{References}

1. Breedlove G, Fryzelka D. Depression screening during pregnancy. J Midwifery Womens Health 2011; 56:18-25. doi: 10.1111/j.1542-2011.2010.00002.x

2. Moses-Kolko EL, Roth EK. Antepartum and postpartum depression: Healthy mom, healthy baby. J Am Med Womens Assoc 2004; 59:181-91.

3. Mohammad KI, Gamble J, Creedy DK. Prevalence and factor associated with the development of antenatal and postnatal depression among Jordanian women. Midwifery 2011; 27:e238-45. doi: 10.1016/j.midw.2010.10.008

4. Chung TK, Lau TK, Yip AS, Chiu HF, Lee DT. Antepartum depressive symptomatology is associated with adverse obstetric and neonatal outcomes. Psychosom Med 2001; 63:830-4. doi: 10.1097/00006842-200109000-00017.

5. Heron J, O'Connor TG, Evans J, Golding J, Glover V; ALSPAC Study Team. The course of anxiety and depression through pregnancy and the postpartum in a community sample. J Affect Disord 2004; 80:65-73. doi: 10.1016/j.jad.2003.08.004.

6. Dailey DE, Humphreys JC. Social stressors associated with antepartum depressive symptoms in low-income African American women. Public Health Nurs 2011; 28:203-12. doi: 10.1111/j.1525-1446.2010.00912.x 
7. Larsson C, Sydsjö G, Josefsson A. Health, sociodemographic data, and pregnancy outcome in women with antepartum depressive symptoms. Obstet Gynecol 2004; 104:459-66. doi: 10.1097/01.AOG.0000136087.46864.e4.

8. Patel V, Rodrigues M, DeSouza N. Gender, poverty, and postnatal depression: A study of mothers in Goa, India. Am J Psychiatry 2002; 159:43-7. doi: 10.1176/appi.ajp.159.1.43.

9. Nasreen HE, Kabir ZN, Forsell Y, Edhborg M. Prevalence and associated factors of depressive and anxiety symptoms during pregnancy: A population based study in rural Bangladesh. BMC Womens Health 2011; 11:22. doi: 10.1186/1472-6874-11-22.

10. Dibaba Y, Fantahun M, Hindin MJ. The association of unwanted pregnancy and social support with depressive symptoms in pregnancy: Evidence from rural Southwestern Ethiopia. BMC Pregnancy Childbirth 2013; 13:135. doi: 10.1186/1471-2393-13-135.

11. Melo EF Jr, Cecatti JG, Pacagnella RC, Leite DF, Vulcani DE, Makuch MY. The prevalence of perinatal depression and its associated factors in two different settings in Brazil. J Affect Disord 2012; 136:1204-8. doi: 10.1016/j.jad.2011.11.023.

12. Ritter C, Hobfoll SE, Lavin J, Cameron RP, Hulsizer MR. Stress, psychosocial resources, and depressive symptomatology during pregnancy in low-income, inner-city women. Health Psychol 2000; 19:576-85. doi: 10.1037/0278-6133.19.6.576.

13. Ministry of National Economy. Oman census summary 2010. From: 85.154.248.117/ MONE2010/\#view=viewCensus Summary\&selectedWafers $=0$ \&selectedColumns $=0,1,2,3$ \&selectedRows $=2,5,7,8,9$ Accessed: Nov 2015.

14. Directorate General Health Services of Muscat, Ministry of Health. From: www.moh.gov.om/en/web/directorate-generalhealth-services-muscat/facilities Accessed: Nov 2015.

15. El Aty MA, Meky FA, Morsy M, El Sayed MK. Overall adequacy of antenatal care in Oman: Secondary analysis of national reproductive health survey data, 2008. East Mediterr Health J 2015; 20:781-8.

16. Cox JL, Holden JM, Sagovsky R. Detection of postnatal depression: Development of the 10-item Edinburgh Postnatal Depression Scale. Br J Psychiatry 1987; 150:782-6. doi: 10.1192/ bjp.150.6.782.

17. Bergink V, Kooistra L, Lambregtse-van den Berg MP, Wijnen $\mathrm{H}$, Bunevicius R, van Baar A, et al. Validation of the Edinburgh Depression Scale during pregnancy. J Psychosom Res 2011; 70:385-9. doi: 10.1016/j.jpsychores.2010.07.008.

18. Alami KM, Kadri N, Berrada S. Prevalence and psychosocial correlates of depressed mood during pregnancy and after childbirth in a Moroccan sample. Arch Womens Ment Health 2006; 9:343-6. doi: 10.1007/s00737-006-0154-8.

19. Gulseren L, Erol A, Gulseren S, Kuey L, Kilic B, Ergor G. From antepartum to postpartum: A prospective study on the prevalence of peripartum depression in a semiurban Turkish community. J Reprod Med 2006; 51:955-60.

20. Nasreen HE, Kabir ZN, Forsell Y, Edhborg M. Low birth weight in offspring of women with depressive and anxiety symptoms during pregnancy: Results from a population based study in Bangladesh. BMC Public Health 2010; 10:515. doi: 10.1186/1471-2458-10-515.

21. Leigh B, Milgrom J. Risk factors for antenatal depression, postnatal depression and parenting stress. BMC Psychiatry 2008; 8:24. doi: 10.1186/1471-244X-8-24.

22. Pawlby S, Hay DF, Sharp D, Waters CS, O'Keane V. Antenatal depression predicts depression in adolescent offspring: Prospective longitudinal community-based study. J Affect Disord 2009; 113:236-43. doi: 10.1016/j.jad.2008.05.018.
23. Hartley M, Tomlinson M, Greco E, Comulada WS, Stewart J, le Roux I, et al. Depressed mood in pregnancy: Prevalence and correlates in two Cape Town peri-urban settlements. Reprod Health 2011; 8:9. doi: 10.1186/1742-4755-8-9.

24. American College of Obstetricians and Gynecologists Committee on Health Care for Undeserved Women. ACOG Committee Opinion No. 343: Psychosocial risk factors Perinatal screening and intervention. Obstet Gynecol 2006; 108:469-77. doi: 10.1097/00006250-200608000-00046.

25. Rich-Edwards JW, Kleinman K, Abrams A, Harlow BL, McLaughlin TJ, Joffe H, et al. Sociodemographic predictors of antenatal and postpartum depressive symptoms among women in a medical group practice. J Epidemiol Community Health 2006; 60:221-7. doi: 10.1136/jech.2005.039370.

26. Islam MM, Dorvlo AS, Al-Qasmi AM. The pattern of female nuptiality in Oman. Sultan Qaboos Univ Med J 2013; 13:32-42. doi: $10.12816 / 0003193$.

27. Dorvlo AS, Bakheit CS, Al-Riyami A, Morsi M, Al-Adawi S. A study of fertility patterns of ever married women in Oman. Sultan Qaboos Univ Med J 2006; 6:33-40.

28. Mirza I, Jenkins R. Risk factors, prevalence, and treatment of anxiety and depressive disorders in Pakistan: Systematic review. BMJ 2004; 328:794. doi: 10.1136/bmj.328.7443.794.

29. Najman JM, Morrison J, Williams G, Andersen M, Keeping JD. The mental health of women 6 months after they give birth to an unwanted baby: A longitudinal study. Soc Sci Med 1991; 32:241-7. doi: 10.1016/0277-9536(91)90100-Q.

30. Bouchard GD. Adult couples facing a planned or an unplanned pregnancy: Two realities. J Fam Issues 2005; 26:619-37. doi: $10.1177 / 0192513 X 04272756$.

31. Bouchard GD. Boudreau JD, Hébert R. Transition to parenthood and conjugal life: Comparisons between planned and unplanned pregnancies. J Fam Issues 2006; 27:1512-31. doi: 10.1177/0192513X06290855.

32. Kuroki LM, Allsworth JE, Redding CA, Blume JD, Peipert JF. Is a previous unplanned pregnancy a risk factor for a subsequent unplanned pregnancy? Am J Obstet Gynecol 2008; 199:517.e1-7. doi: 10.1016/j.ajog.2008.03.049.

33. Noble RE. Depression in women. Metabolism 2005; 54:49-52. doi: 10.1016/j.metabol.2005.01.014.

34. Johanson R, Chapman G, Murray D, Johnson I, Cox J. The North Staffordshire Maternity Hospital prospective study of pregnancy-associated depression. J Psychosom Obstet Gynaecol 2000; 21:93-7. doi: 10.3109/01674820009075614.

35. Lancaster CA, Gold KJ, Flynn HA, Yoo H, Marcus SM, Davis MM. Risk factors for depressive symptoms during pregnancy: A systematic review. Am J Obstet Gynecol 2010; 202:5-14. doi: 10.1016/j.ajog.2009.09.007.

36. Coyne JC, Thompson R, Palmer SC. Marital quality, coping with conflict, marital complaints, and affection in couples with a depressed wife. J Fam Psychol 2002; 16:26-37. doi: 10.1037/0893-3200.16.1.26.

37. Al-Adawi S, Dorvlo AS, Al-Ismaily SS, Al-Ghafry DA, Al-Noobi BZ, Al-Salmi A, et al. Perception of and attitude towards mental illness in Oman. Int J Soc Psychiatry 2002; 48:305-17. doi: 10.1177/002076402128783334.

38. Al-Krenawi A. Mental health practice in Arab countries. Curr Opin Psychiatry 2005; 18:560-4. doi: 10.1097/01.yco.00 00179498.46182.8b. 